\title{
Prediction of Live Body Weight from Body Measurements Using Stepwise Regression Analysis in Sohagi Sheep Elnahas, A. ${ }^{1}$; Manal ElSayed ${ }^{2}$ and M. Elshennawy ${ }^{3}$ \\ ${ }^{1}$ Animal Production Department, Faculty of Agriculture, Sohag University, Egypt \\ ${ }^{2}$ Animal Production Department, Faculty of Agriculture, Ain Sham University, Egypt \\ ${ }^{3}$ Sadat Branch, Environmental studies and Research Institute, Minufiya University, Egypt
}

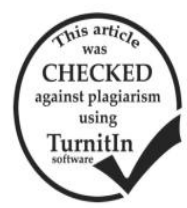

\section{ABSTRACT}

This study aimed at predicting of live body weight from body measurements using stepwise regression analysis. Body measurements data of 212 animals, Sohagi sheep flock (64 male and 148 female) were used. Body weight (BW) and four body measurements were measured: heart girth (HG), height at withers (HW), height at rump (HR) and body length (BL). The stepwise regression analysis was performed in order to retain the $\mathrm{X}$ variable(s) (the body measurements) that contribute significantly $(\mathrm{P}<0.05)$ to the variability in the dependent variable $(\mathrm{BW})$. Results indicated that, there were high and positive correlation coefficients between the body weight and all body measurements. The highest correlation coefficient $(\mathrm{r}=0.93)$ was obtained between BW and HG and the lowest correlation coefficient $(\mathrm{r}=0.88)$ was between BW and BL. All the studied body measurements were entered into the model and through stepwise elimination procedure two of them were considered unfit in the model (HR) and (BL). The two body measurements that best fit the model are heart girth (HG) and height at withers (HW), accounting for $92 \%$ of the live weight in Sohagi sheep. Changes of $\mathrm{R}^{2}$ from the first model $\left(\mathrm{R}^{2}=0.86\right.$, this model included HG only) to the third model $\left(\mathrm{R}^{2}=0.92\right)$, explained that, the most important variable in predicting BW is HG. The standardized coefficient (Beta) is used to explain the contribution of each independent variable in the model. So, the most important variable is $\mathrm{HG}(\mathrm{Beta}=0.92)$, this variable is the most important variable to explain the variability in BW. The prediction equation explained that regression coefficient of $\mathrm{BW} / \mathrm{HG}=0.35$, this means that when the heart girth increases by one unit $(1 \mathrm{~cm})$, the live body weight increases by $0.35 \mathrm{~kg}$ in sohagi sheep.

Keywords: live body weight, Body measurements, stepwise regression and sohagi sheep

\section{INTRODUCTION}

A small flock of sohagi sheep has been formed (2001) by the college of agriculture, sohag university. The body of the Sohagi sheep is shallow, medium in size with an average weight of $40 \mathrm{~kg}$ for females and $65 \mathrm{~kg}$ for males with relatively long neck and legs. The head is small with a straight profile and ewes are mostly polled while rams may be horned and polled. The ears are vestigial. The body is covered with coarse wool ranging from cream to white with cream being dominant (Galal et al., 2002). The sohagi sheep is one of the breeds in Upper Egypt which is considered as important source for meat and wool in Sohag governorate. Type traits have an important influence on sheep performance (Mokhtar-Ali and Farhad GhafouriKesbi, 2011). Body conformation and growth rate of animals are important selection criteria in meat-producing species (Mandal et al., 2008). These measurements, in addition to weight measurements, describe more completely an individual or population than do the conventional methods of weighing and grading (Salako, 2006b) and are of value in predicting live body weight (Mohammed and Amin, 1996).

Using measurement criteria, breeders can be able to identify early maturing and late maturing animals with different sizes (Brown et al., 1973). In a breeding programme, where improved live weight is the main breeding objective, other body measurements having strong correlation to live weight must be considered. The aim of this study is to predict the body weight from heart girth (HG), height at withers (HW), height at rump (HR) and body length (BL) using stepwise regression analysis.

\section{MATERIALS AND METHODS}

This study was carried out in experimental farm of faculty of agriculture, Sohag University. Body measurements data of 212 animals, Sohagi sheep flock (64 male and 148 female) were used. The body weight (BW) and four body measurements (heart girth (HG), height at withers (HW), height at rump (HR) and body length (BL)) were measured, the traits were measured once on each animal during the agricultural year 2017.

Management

Flock was raised under lambing system of three crops per two years. The mating seasons were January, and September. At mating, ewes were divided into groups, each of 30 ewes joined with ram for period 45 days. The flock fed concentrates such as corn and soybean, also green fodder (Trifolium Alexandrium) in the winter was introduced.

Statistical analysis

Test the differences between simple regression coefficients:

Data were divided into four groups according to litter size and six. Group1 (Litter size $=1$ and $\operatorname{sex}=$ female, 94 animals) , Group2 (Litter size $=1$ and sex $=$ male, 35 animals), Group3 (Litter size $=2$ and sex $=$ female, 54 animals ) and Group4 (Litter size $=2$ and sex $=$ male, 29 animals), then simple regression analysis was performed for each group. Weight was the dependent variable and body measurement (HG, HW, HR or BL) was the independent variable according to the following model:

Where,

$$
\mathbf{Y}=\mathbf{a}+\mathbf{b X}+\mathbf{e}
$$

$\mathrm{Y}$ is the observation of body weight

A is the intercept

$X$ is the body measurement (HG, HW, HR or BL)

$b_{y / x}$ is the simple regression coefficient of body weight on body measurement

$e$ is random error assumed to be $\operatorname{NID}\left(0, \sigma_{e}^{2}\right)$.

Then, $\mathrm{T}$ - test was performed to test the differences between the resulted regression coefficients of the four groups.

Stepwise regression analysis

Data of 212 records were analyzed by using the stepwise regression analysis in order to retain the $\mathrm{X}$ variable(s) (the body measurement(s)) that contribute significantly $(\mathrm{P}<0.05)$ to the variability in the 
dependent variable (BW). The following model was used:

\section{$Y=a+b 1 \times 1+b 2 \times 2+b 3 \times 3+b 4 \times 4+$ error}

$\mathrm{Y}$ is the observation of body weight

$A$ is the intercept

b1 is the partial regression coefficient of body weight on heart girth

b2 is the partial regression coefficient of body weight on height at withers

b3 is the partial regression coefficient of body weight on height at rump

b4 is the partial regression coefficient of body weight on body length

e is the residual

* Age was added to the model to correct for its effect.

Detecting multicolinearity

Tolerance and the Variance Inflation Factor (VIF) are two collinearity diagnostic factors that can help in identifying multicolinearity (Kutner et al. 2004 and Statistics solution, 2017). The variable's tolerance is 1$\mathrm{R}^{2}$. A small tolerance value indicates that the variable under consideration is almost a perfect linear combination of the independent variables already in the equation and that it should not be added to the regression equation. All variables involved in the linear relationship will have a small tolerance. Some suggest that a tolerance value less than 0.1 should be investigated further. If a low tolerance value is accompanied by large standard errors and nonsignificance, multicollinearity may be an issue.

The following quantity is deemed the variance inflation factor for the $k^{\text {th }}$ predictor as:

$$
\mathrm{VIF}_{\mathrm{k}}=\mathbf{1} /\left(\mathbf{1}-\mathbf{R}_{\mathrm{k}}^{2}\right)
$$

Where, $R^{2}{ }_{\mathrm{k}}$ is the $R^{2}$-value obtained by regressing the $k^{\text {th }}$ predictor on the remaining predictors. Note that a variance inflation factor exists for each of the $k$ predictors in a multiple regression model. If the VIF coefficient $>10$, it means that the significant correlation between variables could affect the results (Neter et al., 1989)

\section{RESULTS AND DISCUSSION}

Descriptive statistics of live weight and body measurements of Sohagi sheep are shown in Table 1.

Results of Analysis of variance show that, the effects of litter size and sex were highly significant $(p<0.01)$ on all studied variables. Sex had not significant effect $(p>0.05)$ on body length. The mean of single born is better than twins for all studied variables. Male of Sohagi sheep had higher mean values of all studied variables than females.

Table 1. Descriptive statistics (means \pm SE) of studied variables (BW, HG, HW, HR, and BL).

\begin{tabular}{lccccc}
\hline \multirow{2}{*}{$\begin{array}{l}\text { Grand Mean } \\
\text { Fixed Effect }\end{array}$} & $\mathbf{B W ( k g )}$ & $\mathbf{H G}(\mathbf{c m})$ & MW(cm) & HR(cm) & BL(cm) \\
& $\mathbf{4 1 . 7} \pm \mathbf{0 . 6 5}$ & $\mathbf{8 5 . 3} \pm \mathbf{0 . 8 8}$ & $\mathbf{6 8 . 2} \pm \mathbf{0 . 4 8}$ & $\mathbf{7 2 . 8} \pm \mathbf{0 . 4 8}$ & $\mathbf{6 0 . 8} \pm \mathbf{0 . 5 7}$ \\
\hline Litter Size & & & & & \\
1 & $44.04 \pm 0.74$ & $87.65 \pm 1.01$ & $70.34 \pm 0.55$ & $74.80 \pm 0.56$ & $62.30 \pm 0.66$ \\
2 & $39.48 \pm 0.84$ & $83.02 \pm 1.14$ & $66.06 \pm 0.62$ & $70.84 \pm 0.62$ & $59.35 \pm 0.74$ \\
\hline Sex & & & & & $60.13 \pm 0.50$ \\
F & $39.05 \pm 0.57$ & $82.97 \pm 0.77$ & $66.70 \pm 0.42$ & $71.03 \pm 0.42$ & $61.52 \pm 0.91$ \\
M & $44.48 \pm 1.03$ & $87.70 \pm 1.39$ & $69.71 \pm 0.77$ & $74.61 \pm 0.76$ & \\
\hline
\end{tabular}

Estimates of grand mean of body weight and body measurements are lower than those in the study of Gad, 2014. Different estimates probably due to breed differences as well as the feeding and management conditions under which the flock was maintained (Gad, 2014).

Correlation coefficients obtained from stepwise regression analysis between the live weight and body measurements of Sohagi sheep are presented in Table 2.

Table 2. The correlation coefficients between body weight and body measurements

\begin{tabular}{|c|c|c|c|c|c|}
\hline & BW & HG & HW & RH & BL \\
\hline $\mathrm{BW}$ & 1 & & & & \\
\hline $\mathrm{HG}$ & $0.93 * *$ & 1 & & & \\
\hline HW & $0.92 * *$ & $0.93 * *$ & 1 & & \\
\hline $\mathrm{RH}$ & $0.92 * *$ & $0.95 * *$ & $0.99 * *$ & 1 & \\
\hline BL & $0.88 * *$ & $0.90 * *$ & $0.92 * *$ & $0.92 * *$ & 1 \\
\hline
\end{tabular}

There were high and positive correlation coefficients between the live weight and all body measurements. The highest correlation coefficient $(\mathrm{r}=0.93)$ was between $\mathrm{BW}$ and $\mathrm{HG}$, the lowest correlation coefficient $(r=0.88)$ was between BW and BL. The correlation coefficients between body measurements were also positive and significant. These results are similar to the results of Sowande and Sobola, 2007.
This result indicated that, the increase in body measurements (especially HG) will be accompanied by increasing live body weight.

Test the differences between simple regression coefficients of four studied groups:

The following table (Table 3 ) shows the simple regression coefficients of live body weight on body measurements for each group.

Table 3. Simple regression coefficient $\left(b_{y / x}+S E\right)$ of live body weight on body measurements.

\begin{tabular}{lcccc}
\hline \multirow{2}{*}{ Group* } & \multicolumn{4}{c}{ Regression Coefficient } \\
\cline { 2 - 5 } & $\mathbf{b}_{\text {HG/BW }}$ & $\mathbf{b}_{\text {HW/BW }}$ & $\mathbf{b}_{\mathbf{R H} / \mathbf{B W}}$ & $\mathbf{b}_{\mathbf{B L} / \mathbf{B W}}$ \\
\hline 1 & $0.634+0.119$ & $1.170+0.364$ & $-0.980+0.410$ & $0.170+0.149$ \\
2 & $0.508+0.205$ & $0.154+0.628$ & $0.285+0.665$ & $0.326+0.334$ \\
3 & $0.524+0.113$ & $0.508+0.394$ & $0.187+0.421$ & $0.161+0.193$ \\
4 & $0.287+0.124$ & $-1.300+0.560$ & $0.196+0.559$ & $-0.103+0.121$ \\
\hline *Group1(LS1,female), \\
Group2(LS1,male),Group3(LS2,female),Group4(LS2,male) \\
\multicolumn{4}{c}{ The smallest value of simple regression }
\end{tabular}
coefficient was $-0.103\left(\mathrm{~b}_{\mathrm{BL} / \mathrm{BW}}\right)$ in the fourth group and the largest value of regression coefficient was -1.3 $\left(b_{\mathrm{HW} / \mathrm{BW}}\right)$ in the fourth group too. All differences between b's of each two groups were not significant as shown in Table 4. So, stepwise regression was accomplished by using the whole dataset (212 records) regardless the effect of litter size and sex. 
Table 4. T-calculated values for the difference between simple regression coefficients of each two groups.

\begin{tabular}{|c|c|c|c|c|}
\hline Difference & t cal $-b_{\mathrm{BW} / \mathrm{HG}}$ & t cal $-b_{\mathrm{BW} / \mathrm{HW}}$ & t cal $-\mathbf{b}_{\mathrm{BW} / \mathrm{RH}}$ & t cal $-b_{\mathrm{BW} / \mathrm{BL}}$ \\
\hline Group1-Group2 & $0.388 \mathrm{~ns}$ & $1.024 \mathrm{~ns}$ & $-1.176 \mathrm{~ns}$ & $-0.322 \mathrm{~ns}$ \\
\hline Group1-Group3 & $0.474 \mathrm{~ns}$ & $0.873 \mathrm{~ns}$ & $-1.404 \mathrm{~ns}$ & $0.026 \mathrm{~ns}$ \\
\hline Group1-Group4 & $1.427 \mathrm{~ns}$ & $2.673 \mathrm{~ns}$ & $-1.213 \mathrm{~ns}$ & $1.011 \mathrm{~ns}$ \\
\hline Group2-Group3 & $-0.050 \mathrm{~ns}$ & $-0.346 \mathrm{~ns}$ & $0.090 \mathrm{~ns}$ & $0.313 \mathrm{~ns}$ \\
\hline Group2-Group4 & $0.671 \mathrm{~ns}$ & $1.223 \mathrm{~ns}$ & $0.072 \mathrm{~ns}$ & $0.942 \mathrm{~ns}$ \\
\hline Group3-Group4 & $1.00 \mathrm{~ns}$ & $1.895 \mathrm{~ns}$ & $-0.009 \mathrm{~ns}$ & $0.840 \mathrm{~ns}$ \\
\hline
\end{tabular}

ns $=$ not significant

The following table (table 5) shows the results of stepwise regression analysis of live body weight on body measurements.

Table 5. Stepwise regression analysis for live body weight on body measurements (HG, HW, HR and LB).

\begin{tabular}{|c|c|c|c|c|c|c|}
\hline Model & & d.f & $\begin{array}{c}\text { Mean } \\
\text { square }\end{array}$ & $\mathbf{F}$ & Sig & $\begin{array}{c}\mathbf{R}^{2} \\
\text { square }\end{array}$ \\
\hline \multirow[t]{3}{*}{1} & Regression & 1 & 59967.60 & 1270.9 & $.000^{\mathrm{a}}$ & .86 \\
\hline & Residual & 210 & 47.11 & & & \\
\hline & Total & 211 & & & & \\
\hline \multirow[t]{3}{*}{2} & Regression & 2 & 31458.01 & 946.72 & $.000^{\mathrm{b}}$ & .90 \\
\hline & Residual & 209 & 33.22 & & & \\
\hline & Total & 211 & & & & \\
\hline \multirow[t]{3}{*}{3} & Regression & 3 & 21428.38 & 799.39 & $.000^{\mathrm{c}}$ & .92 \\
\hline & Residual & 208 & 26.80 & & & \\
\hline & Total & 211 & & & & \\
\hline
\end{tabular}

a. Predictors: (Constant), HG

b.Predictors: (Constant), HG and age

c. Predictors: (Constant), HG, age and HW

All the studied body measurements were entered into the model and through stepwise elimination procedure two of them were considered unfit in the model (HR) and (BL). The two body measurements that best fit the model are heart girth (HG) and height at withers (HW) accounting for $92 \%$ (in addition to age) of variability of the live body weight in Sohagi sheep .

$\mathrm{R}^{2}$ changes from the first step (HG only, $\mathrm{R}^{2}=0.86$ ) to the second step $\left(\mathrm{HG}\right.$, age, $\left.\mathrm{R}^{2}=0.90\right)$ and third step $(\mathrm{HG}$, age and $\mathrm{HW}, \mathrm{R}^{2}=0.92$ ), explain that, the most important variable in predicting $\mathrm{BW}$ is HG. These results are similar to the results of Sowande and Sobola, 2007, but estimates of $\mathrm{R}^{2}$ were higher than those of the mentioned study.

Table (6) shows the regression coefficients and the collinearity statistics, also the standardized coefficient (Beta) which is used to explain the contribution of each independent variable in the model. So, the most important variable is HG (Beta $=0.92)$, this variable is the most important variable to explain the variability in $\mathrm{BW}$, where the smallest Beta is 0.37 for HW. These results agree with the previous results of $\mathrm{R}^{2}$, that $\mathrm{HG}$ is the most important body measurement to predict live body weight in sohagi sheep. A negative value for intercept should not be a cause for concern; this simply means that the expected value of dependent variable will be less than 0 when all independent variables are set to 0 . This estimate is the expected mean response when all the explanatory predictors are at zero.
Table 6. Regression parameters for estimating body weight from body measurements and collinearity statistics

\begin{tabular}{llcccc}
\hline \multirow{2}{*}{ Model Parameter } & $\begin{array}{c}\text { Regression } \\
\text { coefficient }\end{array}$ & Beta & \multicolumn{2}{c}{$\begin{array}{c}\text { Collinearity } \\
\text { Statistics }\end{array}$} \\
\cline { 5 - 6 } & & & & \\
tolerance & VIF \\
\hline \multirow{2}{*}{2} & Intercept & -29.87 & & & \\
& $\mathrm{~b}_{\mathrm{BW} / \mathrm{HG}}$ & 0.83 & 0.93 & 1.000 & 1.000 \\
& Intercept & -21.69 & & & \\
& $\mathrm{~b}_{\mathrm{BW} / \mathrm{HG}}$ & 0.65 & 0.73 & 0.51 & 1.95 \\
& $\mathrm{~b}_{\mathrm{BW} / \mathrm{age}}$ & 0.24 & 0.29 & 0.51 & 1.95 \\
3 & Intercept & -34.73 & & & \\
& $\mathrm{~b}_{\mathrm{BW} / \mathrm{HG}}$ & 0.35 & 0.39 & 0.13 & 7.56 \\
& $\mathrm{~b}_{\mathrm{BW} / \mathrm{age}}$ & 0.23 & 0.27 & 0.51 & 1.96 \\
& $\mathrm{~b}_{\mathrm{BW} / \mathrm{HW}}$ & 0.57 & 0.37 & 0.14 & 6.94 \\
\hline
\end{tabular}

It is important to test the collinearity by using tolerance and VIF coefficients (Table 6). If tolerance coefficient $<0.1$, this means that the correlation coefficients between independent variables could affect the results of the regression analysis. Also, if the VIF coefficient $>10$, it means that the significant correlation between variables could affect the results of regression analysis. Estimates of tolerance and VIF in table 6 show that tolerance coefficient $>0.1$ and VIF coefficient $<10$, so the correlation coefficients between independent variables did not affect the results of the regression analysis.

Prediction equations of stepwise regression analysis From Table (6), the following equation represents the prediction equation:

$\mathrm{BW}=\mathbf{- 3 4 . 7 3}+\mathbf{0 . 3 5}(\mathrm{HG})+\mathbf{0 . 2 3}($ age $)+0.57(\mathrm{HW})$

All regression coefficients are positive and significant $(\mathrm{P}<0.01)$.

The regression coefficient of $\mathrm{BW} / \mathrm{HG}=0.35$, this means that, when the heart girth increases by one unit $(1 \mathrm{~cm})$, the live body weight increases by $0.35 \mathrm{~kg}$

\section{CONCLUSION}

The results obtained in this study indicated that for a breeder or stockman to have a fairly good knowledge of the live weight of Sohagi sheep, measurement of HG will be useful. Selection and breeding based on this body measurement could result in improved live weight in Sohagi sheep.

\section{ACKNOWLEDGEMENT}

The authors would like to thank Prof. Dr. Hussein Mansour, Professor of Animal Breeding, Faculty of Agriculture, Ain Shams University for his valuable advice in statistical analysis. 


\section{REFERENCES}

Abbasi,M.A. and F. G. hafouri-Kesbi(2011). Genetic (Co) variance components for body weight and body measurements in Makooei Sheep. AsianAust. J. Anim. Sci. Vol. 24, No. 6: 739- 743 www.ajas.info. doi: 10.5713/ajas.2011.10277

Brown, J.E., Brown, C.J. and Butts, W.T. (1973). Evaluating relationships among immature measures of size, shape and performance of beef bulls. J. Anim. Sci. 36, 1010-1020

Gad, S.M.A. (2014). Estimation of genetic parameters for body measurements and their relationship with body weight in barki lambs. Animal and Poultry Breeding Dept., Desert Research Centre, Cairo, Egypt. J.Animal and Poultry Prod., Mansoura Univ., Vol.5 (8): 517 - 523, 2014

Galal, S., Ferial Abdel Rasoul, M. R. Anous and I. Shaat (2002). On-station characterization of small ruminant breeds in Egypt, ICARDA, Aleppo, Syria, 78 pp.

Kutner, M.H.; Nachtsheim, C.J. and Neter, J. (2004). Applied Linear Regression Models (4th ed.). McGraw-Hill Irwin. Statistics Solutions 2017, http://www.statisticssolutions.com/new/about-us-page
Mandal, A., R. Roy and P.K. Rout. (2008). Direct and maternal effects for body measurements at birth and weaning in Muzaffarnagari sheep of India. Small Rumin. Res. 75:123-127.

Mohammed, I. D. and J. D. Amin. 1996. Estimating body weight from morphometric measurements of Sahel (Borno White) goats. Small Rumin. Res. 24:1-5.

Neter, J., Wasserman, W. and Kutner, M.H. (1989). Applied Linear Regression Models. Irwin Publ., 2nd edn. Boston, p: 229-292

Salako, A.E. (2006b). Principal component factor analysis of the morphostructure of immature Uda sheep. Int. J. Morph. 24: 571-574.

Sowande O.S. and O.S. Sobola (2007). Body measurements of west African dwarf sheep as parameters for estimation of live weight. Accepted: 24 November 2007 / Published online: 6 December 2007 \# Springer Science+ Business Media B.V. 2007 Trop Anim Health Prod (2008) 40:433-439 DOI 10.1007/s1 1250-007-9116-z

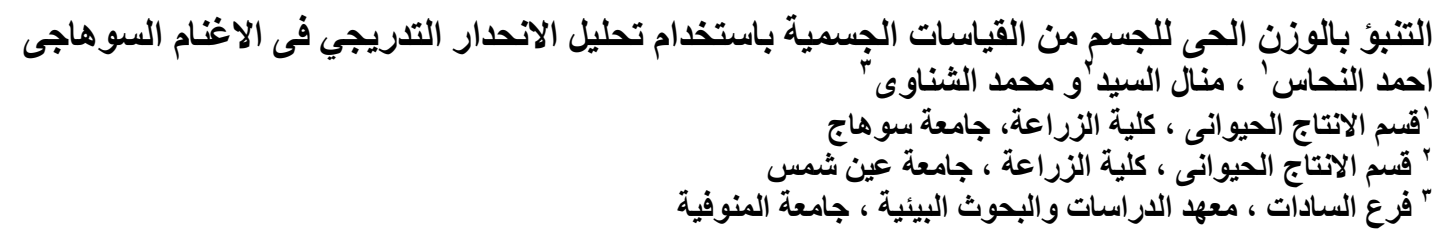

الهدف من هذه الدراسة هو التتبؤ بالوزن الحى من خلال القياسات الجسمية باستخدام نموذج تحليل الانحدار التدريجي. بيانات

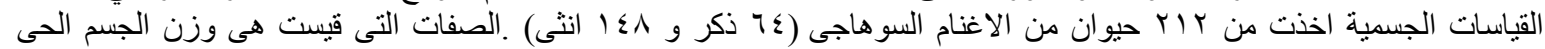

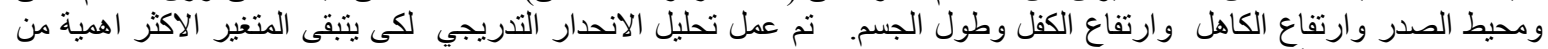

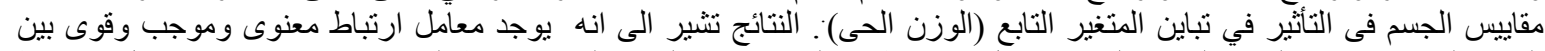

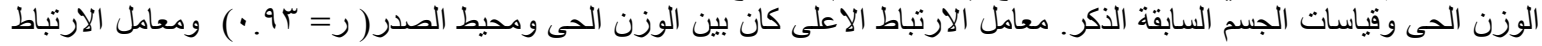

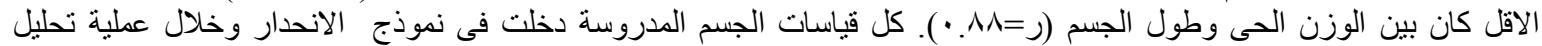

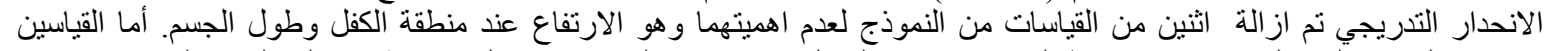

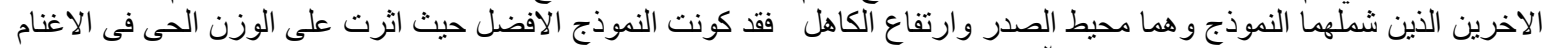

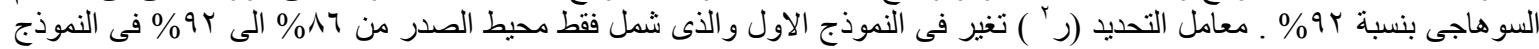

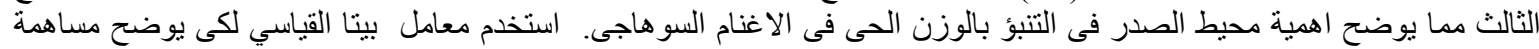

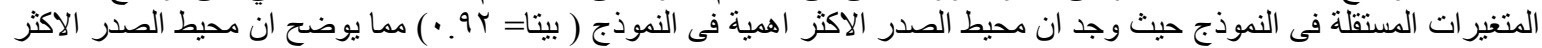

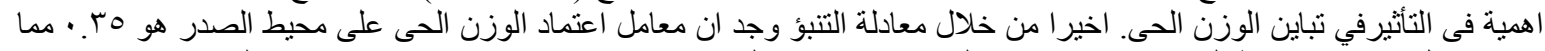

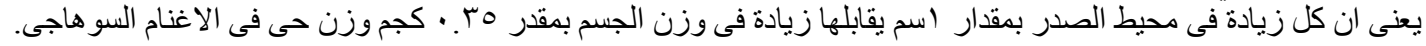

